\title{
A influência de fatores socioculturais nas atitudes face à homossexualidade: Estudo comparativo
}

\author{
The influence of sociocultural factors on attitudes towards \\ homosexuality: Comparative study
}

\author{
M. Gomes, S. Assunção, S. Azevedo, C. M. Teixeira
}

ARTIGO ORIGINAL | ORIGINAL ARTICLE

\begin{abstract}
RESUMO
A forma como a sociedade vê a homossexualidade sofreu alterações ao longo do tempo, sendo o objetivo deste estudo perceber de que forma é vista a homossexualidade na atualidade, tendo por base diferentes variáveis: sexo, meio (rural/urbano), idade, religiosidade, contacto interpessoal LGBT, habilitações académicas e o setor profissional. Este estudo foi do tipo quasi-experimental e de caráter transversal. A amostra foi de 192 indivíduos, 97 mulheres e 95 homens. Aplicou-se um questionário sociodemográfico e uma Escala Multidimensional de Atitudes Face a Lésbicas e Gays (EMAFLG). Os resultados evidenciaram valores mais elevados nas subescalas negativas e mais baixos na subescala positiva relativas à perceção da homossexualidade concluindo que os homens, os indivíduos que passaram a maior parte da sua vida em meio rural, as pessoas com mais idade, os indivíduos que se consideram religiosos, aqueles que não possuem contacto com LGBT, os que possuem habilitações académicas mais baixas e por fim os indivíduos que trabalham numa área do setor secundário são mais homofóbicos. Concluiu-se que existe preconceito relativamente à homossexualidade.
\end{abstract}

Palavras-chave: homossexualidade, atitudes, homofobia, preconceito

\begin{abstract}
The way society views homosexuality has changed over time. The purpose of this study is to understand how homosexuality is considered today, based on different variables gender, environment (rural/urban), age, religiosity, interpersonal contact with LGBT, academic qualifications, and the professional sector. The sample was 192 individuals, 97 women, and 95 men. A sociodemographic questionnaire and a Multidimensional Lesbian and Gay Attitudes Scale (EMAFLG) were applied. The statistical program used for data analysis was the statistical package for the Social Sciences (SPSS). The results obtained presented statistically significant differences for all variables except for the variable sex. Comparisons by residential areas showed that individuals living in rural areas, older people, individuals who consider themselves religious, those who do not have contact with LGBT, those with lower academic qualifications, and, lastly, individuals working in a secondary sector are more homophobic. It was concluded that there are still prejudices regarding homosexuality.

Keywords: homosexuality, attitudes, homophobia, preconception
\end{abstract}

Submetido: 07. 17.2017 | Aceite: 03.24.2018

Mara Mendonça Gomes, Sandra Assunção, Solange Azevedo. Health \& Performance Psych Lab. Gab.2.27, ECHS-1, Quinta de Prados, 5000-881, Vila Real, Portugal.

Endereço para correspondência: Carla M. Teixeira, Health \& Performance Psych Lad. MASSIVE INESCT TEC - Pólo UTAD. Dept. Educação e Psicologia. Quinta de Prados, 5000-881, Vila Real, Portugal. E-mail: cteixeir@utad.pt 
A forma como a sociedade vê a homossexualidade sofreu alterações ao longo do tempo. Em diferentes civilizações antigas da América do Sul, da Ásia e até da África a homossexualidade era considerada normal, No entanto, a partir do século XV a não-heterossexualidade começou a ser vista como anormal nos povos cristãos, em Israel, até que se difundiu pelo mundo. Esta alteração para a anormalidade homossexual terá aparecido devido às crenças e aos valores defendidos pelo Cristianismo (Poeschl, Venâncio, \& Costa, 2012).

A orientação sexual do ser humano pode ser definida como heterossexual, que é designada pela atração por alguém do sexo oposto; homossexual, que é a atração por outro ser do mesmo sexo, e bissexual, que se refere à atração por pessoas de ambos os sexos (Reis et al., 2016). Para Santos (2012), a homossexualidade é uma orientação e não uma opção ou preferência sexual, isto é, à priori, os indivíduos não decidem ser homossexuais. Michaels e Lhomond (2006) consideram que a homossexualidade, para além do comportamento, depende de aspetos psicológicos e cognitivos como o desejo sexual. A identidade homossexual depende também do contexto social e cultural em que o indivíduo se insere. Também Bozon, Gayet e Barrientos (2009) consideram que o comportamento sexual varia de região para região devido à diversidade dos determinantes sociais, culturais e económicos.

Durante muito tempo a homossexualidade foi considerada uma psicopatologia, tendo sido retirada do Manual de Diagnóstico de Perturbações Mentais (DSM) da Associação Americana de Psiquiatria em 1973 e só em 1990 é que a Organização Mundial da Saúde retirou a homossexualidade da lista de doenças da Classificação Estatística Internacional de Doenças e Problemas Relacionados com a Saúde, o CID-10 (Santos, 2013). Com a evolução da sociedade, a insistência em direitos de igualdade e a visão de que a homossexualidade não é uma doença, pensa-se que o preconceito e a discriminação para com esta minoria tenham diminuído, se bem que esta continue a existir, ainda que seja menos evidenciada (existe de forma oculta), ma vez que a sua aceitação tenha vindo a evoluir (Gato, Fontaine, \& Carneiro, 2012; Gato, Fontaine, \& Leme, 2014; Costa \& Nardi, 2015), em parte por que ainda se verifica a prescrição sociocultural da heterossexualidade (Gato \& Fontaine, 2012). Estudos mostram que os portugueses ficam menos à vontade quando na presença de pessoas não heterossexuais, assim como também seja menos provável terem amigos ou pessoas conhecidas fora da norma heterossexual, quando comparados com outros países (Gato et al., 2014). A homofobia é o termo que se usa para qualificar os indivíduos que discriminam outros por terem uma orientação sexual diferente da sua. Existem vários comportamentos homofóbicos que são abusivos das liberdades individuais, como por exemplo agressões físicas, psicológicas e sexuais em relação a pessoas não-heterossexuais ou que se revejam com essa orientação (Fazzano \& Gallo, 2015).

A perceção negativa da homossexualidade pode ter as suas raízes em papéis de género mais conservadores e tradicionais (Gato et al., 2014). Segundo Carvalho, Pinheiro, Martins, Simões e Maceiras (2017), a discriminação com base na orientação sexual manifesta-se de várias formas e tem consequências diversas, ela pode partir de uma simples piada até ao insulto ou agressão física, podendo ocorrer em qualquer interação social da pessoa. O termo "heterossexismo" é definido como um conjunto de valores que origina uma atitude de negação e/ou inferioridade contra todos os indivíduos não-heterossexuais. Já o "preconceito sexual" refere-se à discriminação de alguém com base na sua orientação sexual (Gato et al., 2014).

Ser homem ou mulher tem vindo a ser apontado, por diferentes estudos, como um fator 
preditor da perceção da homossexualidade. Por exemplo, Gusmão et al. (2016) concluíram que existem diferenças na expressão da homofobia entre homens e mulheres, sendo que os homens mostraram ser mais homofóbicos do que as mulheres. Segundo Gato, Fontaine, Leme e Leme (2015) quando se trata das normas de género as mulheres são mais tolerantes e flexíveis do que os homens. Num estudo de Gato et al. (2012), as mulheres revelaram valores mais elevados nos aspetos positivos da escala e valores mais baixos nos aspetos negativos, quando comparadas com os homens. As mulheres demonstraram níveis de aceitação mais positivos do que os homens, na perceção da homossexualidade. Essas diferenças apresentam-se mais acentuadas quando o que está em causa são as relações entre dois homens (Fleury \& Torres, 2007; Gomes \& Serôdio, 2014; Reis et al., 2016).

A idade também pode influenciar a perceção da homossexualidade, em que pessoas com idade mais avançada tendem a estigmatizar mais os indivíduos não-heterossexuais (Costa \& Nardi, 2015). Resultados semelhantes foram obtidos no estudo de Gomes e Serôdio (2014) que evidenciaram que são os adultos com mais idade que tendem a ser menos tolerantes e mais desfavoráveis em relação a pessoas homossexuais. Também Reis et al. (2016) e Nota, Vilaça e Mabote (2012) concluíram que os indivíduos mais novos, neste caso dos 18 aos 25 anos, demonstram ter uma opinião mais positiva, ou seja, uma melhor aceitação da homossexualidade do que os participantes mais velhos.

Quanto ao nível de interação interpessoal com pessoas LGBT, vários estudos têm evidenciado que as pessoas que não conhecem lésbicas e/ou gays, expressam atitudes mais negativas relativamente às pessoas LGBT's (lésbicas, gays, bissexuais e transexuais), do que aquelas que têm contacto com as mesmas (Gato et al., 2012). As pessoas que têm ou tiveram contacto com indivíduos não-heteros- sexuais tendem a ser menos preconceituosas (Costa \& Nardi, 2015). Dessa forma, Gato et al. (2012) mostraram que quem possuía contacto interpessoal com LGBT apresentava uma atitude positiva face à homossexualidade, ao invés das pessoas que não tinham contacto interpessoal com LGBT. Verificou-se o mesmo noutro estudo, que demonstrou que quanto maior era a familiaridade dos participantes com homossexuais, mais favorável eram as suas atitudes e menor as suas rejeições de proximidade com essas pessoa. Ou seja, o contacto interpessoal influencia a perceção e as atitudes que os indivíduos têm em relação a não-heterossexuais (Gomes \& Serôdio, 2014). Ter amigos gays e lésbicas pode servir para atenuar a associação positiva entre o fundamentalismo religioso e o preconceito sexual, onde é possível que as amizades com minorias sexuais levem as pessoas a reavaliarem as suas atitudes em relação a lésbicas e gays (Cunningham \& Melton, 2012). O estudo de Adela (2010) concluiu que pessoas com pouco contacto com homossexuais, menores habilidades académicas e pouco informadas acerca da homossexualidade possuem uma visão mais negativa da mesma. Possuir amigos ou parentes homossexuais foi correlacionado de forma positiva com a perceção positiva da homossexualidade, bem como o nível educacional (Feng et al., 2012).

Gomes e Serôdio (2014) mostraram que a escolarização também influencia a atitude face à homossexualidade, existindo atitudes mais favoráveis em pessoas mais escolarizadas e menos favoráveis em pessoas com menos escolarização. Para Costa e Nardi (2015) um maior grau de escolaridade está associado a um menor grau de preconceito face à homossexualidade, e uma maior aceitação da mesma.

As pessoas que ão religiosas e que defendem ideologias morais mais conservadoras e valorizam os valores tradicionais da religião e lhe oferecem obediência apresentam uma 
perceção mais negativa acerca da homossexualidade, que ao olhos destes tende a ser consideradoa como um pecado e um desrespeito das leis de Deus. O oposto ocorre em pessoas mais liberais (Chonody, Woodford, Smith, \& Silverschanz, 2013; Gomes \& Serôdio, 2014; Gusmão et al., 2016; Pereira, Dias, Lima, \& Sousa 2017). Santos, Carvalho, Nunes e Silveira (2017) relacionaram a religiosidade com a homofobia e mostraram que quem tem altos níveis de religiosidade apresenta atitudes mais homofóbicas. Assim, a religião continua a ser um meio de controlo social que regula os valores morais e difunde aquilo que é visto como certo e/ou errado, onde toda a prática que seja homossexual é uma afronta à "determinação divina". A homossexualidade tem sido, assim, condenada pela religião e servindo de alicerce para os juízos de valor e do comportamento das pessoas. Também no estudo de Barringer, Gay e Lynxwiler (2013) e Harbaugh e Lindsey (2015) os resultados evidenciam a existência foram de relações entre a religião e as atitudes em relação à homossexualidade, onde o nível de comprometimento do indivíduo com os ensinamentos religiosos afeta as atitudes em relação aos indivíduos com essa orientação sexual em que os indivíduos que frequentam serviços religiosos com mais frequência são menos tolerantes em relação à homossexualidade. Para este indivíduos, aos olhos da religião a homossexualidade é um pecado e que por isso existem sanções eternas para aqueles que se envolvem em comportamentos homossexuais.

Viver num meio urbano constitui um fator protetor para as pessoas não-heterossexuais, uma vez que nestas áreas residenciais as pessoas encontram maiores e melhores redes de apoio social. Viver num meio urbano também oferece a possibilidade de uma maior satisfação nas suas vidas, uma vez que estão inseridos num meio social que lhes permite ter maior sucesso nos seus relacionamentos íntimos (Delgado, Castro, \& Ojeda, 2014;
Feng et al., 2012).

A literatura também sugere que o estrato profissional e que as pessoas se inserem também influencia os níveis de tolerância. Existem diferentes setores profissionais: o primário diz respeito a atividades extrativas essenciais para a sobrevivência como a agricultura e criação de gado; o secundário implica atividades produtivas de maior escala e é referente à indústria e manufatura; e o terciário refere-se aos serviços como o comércio e prestação de serviços (e.g. saúde, educação, informática, serviços sociais, etc.) (Kon, 1999). Carvalho e Philippi (2013) concluíram que a maioria dos LGBT se sente discriminada quando frequenta serviços de saúde sejam eles públicos ou privados. Este resultado foi relatado por cerca de metade da amostra (43.33\%) e indica que profissionais de saúde tendem a ter atitudes negativas perante a não-heterossexualidade. Existe discriminação face à orientação sexual em profissões quer nos contextos da justiça, da saúde e da educação. Existe discriminação por parte de profissionais cujo papel é o de promover o bem-estar e proteger os direitos das pessoas e suas famílias, independentemente da orientação sexual (Gato \& Fontaine, 2012). Mais concretamente, os transexuais, que têm bastantes dificuldades em se inserirem no mercado de trabalho, tendem a ser vítimas de preconceito e discriminação em instituições que são prestadoras de serviços públicos, devido às suas mudanças corpóreas (Júnior, Carvalho, \& Ramalho, 2013). Também nas instituições de ensino é frequente o recurso ao bullying homofóbico, fazendo com que muitas vezes as vítimas se afastem do ambiente educacional (Pereira, Varela, \& Silveira, 2015). Mesmo por parte dos professores ainda existem muitas contradições na educação sexual, com atitudes discriminatórias, nas quais rotulam e excluem esse grupo (Maciel \& Garcia, 2014). Em ambiente militar, a homossexualidade é considerada um tabu, onde se evita falar do assunto 
e os homossexuais são quase "obrigados" a esconder a sua orientação sexual, pois daqueles que se assumem, muitos continuam a ser discriminados e punidos (Leite \& Neto, 2013). O estudo de Garcia e Souza (2010), avaliou a discriminação existente em funcionários de bancos públicos e privados, e verificou que existia uma elevada discriminação em relação aos homossexuais nesta profissão do setor terciário. Para que haja uma maior aceitação desta minoria (não-heterossexuais) seria importante planear ações pedagógicas que sensibilizassem crianças e adolescentes (Gonzaga, Praça, \& Lannes, 2014).

Num tempo em que se promove como valor central para a realização pessoal a liberdade de escolha e que cada um seja responsável pela construção da sua felicidade, é importante compreender como alguns agentes sociais persistem na defesa de valores e crenças que indiretamente interferem na liberdade dos outros.

Face ao exposto, o objetivo deste estudo foca-se em perceber de que forma é vista a homossexualidade na atualidade, tendo por base diferentes variáveis sociodemográficas como o sexo, o meio onde passou a maior parte da sua vida (rural/urbano), a idade, a religiosidade, o contacto com indivíduos LGBT, as habilitações académicas e por fim, o setor profissional.

Os objetivos específicos deste estudo consistem em: comparar as diferenças na perceção da homossexualidade entre homens e mulheres; avaliar se existe influência do meio (rural/urbano) na perceção da homossexualidade; avaliar se a idade influencia a perceção da homossexualidade; avaliar se a religiosidade influencia a perceção da homossexualidade; comparar a perceção da homossexualidade entre participantes com e sem contacto interpessoal com pessoas LGBT; avaliar se as habilitações académicas influenciam a perceção da homossexualidade e por fim comparar a perceção da homossexualidade nos diferentes setores profissionais.

\section{MÉTODO}

Este estudo é do tipo quasi-experimental (amostra por conveniência e variáveis independentes não controladas), de caráter transversal, uma vez que os dados são recolhidos num único momento e permite descrever associações entre variáveis. Possui um caráter quantitativo.

\section{Amostra}

Neste estudo participaram 192 indivíduos residentes no Norte de Portugal escolhidos de forma não aleatória (por conveniência) dos quais 97 mulheres ( $47 \leq 25$ anos e as restantes com $\geq 50$ anos) e 95 homens (49 com $\leq 25$ anos e os restantes com $\geq 50$ anos). A média das idades dos jovens adultos ( $\leq 25$ anos) foi de 20.59 anos $(\mathrm{DP}=1.88)$ e dos adultos $(\geq 50$ anos) foi de 57.34 ( $\mathrm{DP}=6.86)$. Dos 192 participantes: 174 eram heterossexuais, 10 homossexuais e 8 bissexuais; 104 viviam em meio rural e 88 em meio urbano; 92 possuíam relações com LGBT's, 71 não possuíam e 29 não sabiam se possuíam; 44 tinham no máximo o $6^{\circ}$ ano de escolaridade, 13 tinham entre o $7^{\mathrm{a}} \mathrm{e}$ $9^{\circ}$ ano, 30 concluíram o ensino secundário e 105 frequentam ou concluíram o ensino superior; 150 afirmam ser religiosos e 42 não religiosos; 8 têm profissões do setor primário, 31 do setor secundário e 52 do terciário, 1 desempregado e 14 reformados. Há um certo desequilibrio nas constituição dos grupos estudados, mas, em parte, isto resulta do facto da recolha ter sido feita numa região onde estão inseridas várias instituições de superior e localizadas numa zona interior as mais pobres do país.

Todos os participantes foram informados acerca dos objetivos do estudo e assinaram um consentimento informado.

\section{Instrumentos}

O primeiro instrumento utilizado foi um questionário sociodemográfico construído com base na identificação da variáveis independentes dos estudos revistos e que no geral incluía questões sobre idade, sexo, local onde viveu a maior 
parte da sua vida (rural ou urbano), habilitações académicas $\left(1^{\circ}\right.$ ou $2^{\circ}$ ciclo; $3^{\circ}$ ciclo; secundário; ensino superior), profissão (setor primário, secundário, terciário e estudante), religião (é religioso ou não é) e se possuem contacto interpessoal com LGBT.

O segundo instrumento foi a Escala Multidimensional de Atitudes Face a Lésbicas e Gays (EMAFLG). É uma escala de resposta tipo Likert em que os participantes expressam a sua opinião para cada um dos itens de 1 (discordo completamente) a 6 (concordo completamente). Esta foi validada em Portugal por Gato et al. (2012), inicialmente com uma Análise Fatorial Exploratória e em 2014 através de uma Análise Fatorial Confirmatória por Jorge , Anne Marie Fontaine e Vanessa Leme. É constituída por 27 itens, distribuídos em três subescalas negativas: Homopatologização com cinco itens que avaliam os juízos morais e patologizadores acerca da homossexualidade $(\alpha=.86)$, Rejeição de Proximidade com dez itens que traduzem o evitamento do contato com lésbicas e gays em diversos contextos sociais e a manifestação de desconforto emocional na sua presença $(\alpha=.91)$, Heterossexismo Moderno com sete itens relacionados com manifestações contemporâneas do preconceito contra lésbicas e gays referindo-se à conjugalidade e à parentalidade $(\alpha=.79) \mathrm{e}$ uma subescala positiva: Suporte com cinco itens que avaliam a legitimidade da defesa dos direitos das lésbicas e gays ( $\alpha=.83$ ) (Gato et al. 2015; Gato et al., 2014; Gato et al., 2012). No que diz respeito à consistência interna do total da escala, o Alfa de Cronbach é $\alpha=.87$ (Gato et al., 2014).

\section{Procedimentos}

A recolha de dados foi realizada no norte de Portugal. Esta recolha foi antecedida pelo consentimento informado, livre e esclarecido, que permitiu o conhecimento do objetivo do estudo, assegurou que a participação era voluntária e que os dados fornecidos seriam anónimos e confidenciais. O estudo foi previamente revisto e aprovado pela Comissão de ética. De seguida, os participantes responderam a um questionário sociodemográfico, bem como, à Escala Multidimensional de Atitudes Face a Lésbicas e Gays. A recolha da amostra foi realizada de forma individual, sendo que o preenchimento do questionário demorou no máximo 15 minutos. As investigadoras estiveram presentes para responder a eventuais dúvidas.

\section{Análise Estatística}

Foi realizada a análise estatística descritiva dos dados, tendo estes sido apresentados através da média $(\mathrm{M})$ e desvio padrão (DP). Para verificar a normalidade dos dados foram calculados os coeficientes de assimetria e curtose, devendo estes estar entre -2 e 2 para a amostra apresentar uma distribuição normal. Foi avaliada a existência de relação entre as variáveis, através de uma análise de variância multivariada (MANOVA), de modo a comparar diferenças entre sexo, local onde passou a maior parte da sua vida, idade, religiosidade, contacto com indivíduos LGBT, habilitações académicas e por fim o setor profissional, analisando o efeito de magnitude $\left(\eta_{p}^{2}\right)$ relatado como uma medida do tamanho do efeito entre as variáveis de acordo com a seguinte regra geral: pequeno $(>.01)$, médio $(>.06)$ e grande $(>.14))$ sendo este valor a probabilidade de se extrapolar para a população os resultados obtidos (generalização dos dados), bem como o poder observado (PO) sendo esta medida representativa da probabilidade de num estudo futuro com uma amostra semelhante serem obtidos resultados idênticos. Para a análise de dados recorreu-se ao programa estatístico Statistical Package for the Social Sciences (SPSS).

Relativamente aos factores associados à validade interna, no decorrer do estudo não se verificaram quaisquer registos de desconforto, desistência ou preenchimento inadequado dos instrumentos. Quanto à validade externa os instrumentos utilizados estavam devidamente validados para a população em estudo. 


\section{RESULTADOS}

No que se refere à comparação da perceção da homossexualidade entre homens e mulheres obteve-se através da MANOVA: $\mathrm{F}_{(4.184)}=2.250, p=.65, \eta_{p}^{2}=.047$, Wilks $-\lambda=$ $.953, P O=.651$. Como $p>.05(p=.621)$. Não se verificam diferenças estatisticamente signi- ficativas entre homens e mulheres, o efeito de magnitude é baixo $(<.06)$ tal como o poder observado (.212). Conforme é possível verificar no quadro 2 , não houve efeito de magnitude $\left(\eta_{p}^{2}<.01\right)$ em nenhuma subescala e o poder observado mais elevado é de .14, sendo estes valores muito baixos.

Quadro 2

Média (M), desvio-padrão (DP) e efeitos das dimensões da perceção acerca da homossexualidade por sexo

\begin{tabular}{|c|c|c|c|c|c|c|}
\hline & \multicolumn{2}{|c|}{ Sexo } & \multirow{2}{*}{$F$} & \multirow{2}{*}{$p$} & \multirow{2}{*}{$\eta_{p}^{2}$} & \multirow{2}{*}{$P O$} \\
\hline & $\begin{array}{l}\text { Masculino } \\
\text { M } \pm D P\end{array}$ & $\begin{array}{l}\text { Feminino } \\
M \pm D P\end{array}$ & & & & \\
\hline Rejeição de Proximidade & $31.564 \pm 4.314$ & $31.433 \pm 5.270$ & .002 & .963 & .000 & .050 \\
\hline Homopatologização & $11.638 \pm 6.901$ & $9.742 \pm 5.923$ & .097 & .756 & .001 & .061 \\
\hline Heterossexismo Moderno & $22.202 \pm 5.198$ & $20.196 \pm 5.823$ & .562 & .455 & .003 & .116 \\
\hline Suporte & $20.989 \pm 5.021$ & $23.041 \pm 5.439$ & .782 & .378 & .004 & .142 \\
\hline
\end{tabular}

No que se refere à comparação entre pessoas do meio rural e urbano, obteve-se: $\mathrm{F}_{(4.184)}=$ $3.455, p=.009, \eta_{p}^{2}=.070$, Wilks $-\lambda=.930, P O$ $=.851$. Como $p<.05(p=.009)$ verificaram-se diferenças estatisticamente significativas no que diz respeito à perceção da homossexualidade entre pessoas que viveram maioritariamente em meios rurais e urbanos. Quanto ao efeito de magnitude conclui-se que é moderado e o poder observado elevado (.851).

No quadro 3 é possível verificar que as principais diferenças estão na subescala negativa Homopatologização $(p=.005)$ com um efeito de magnitude baixo $(<.06)$ e um elevado poder observado (.813). Nas restantes subescalas não se verificam diferenças significativas, os efeitos de magnitude são baixos $(<.06)$ e os poderes observados também apresentam baixos valores, sendo o mais elevado 399 na Rejeição de Proximidade.

Para comparar a perceção da homossexualidade entre o sexo e o meio, realizou-se uma MANOVA, da qual se obteve: $\mathrm{F}_{(4.184)}=1.309$, $p=.268, \eta_{p}^{2}=.028$, Wilks $-\lambda=.972, P O=$ .404 . Como $p>.05$, não se verificam diferenças estatisticamente significativas na relação entre o sexo e o meio, ou seja, ser do sexo feminino e viver maioritariamente em meio rural ou urbano não tem diferenças na perceção da homossexualidade, o mesmo acontece com o sexo mascu-

Quadro 3

Média (M), desvio-padrão (DP) e efeitos das dimensões da perceção da homossexualidade por meio

\begin{tabular}{|c|c|c|c|c|c|c|}
\hline & \multicolumn{2}{|c|}{ Meio } & \multirow{2}{*}{$F$} & \multirow[b]{2}{*}{$p$} & \multirow[b]{2}{*}{$\eta_{p}^{2}$} & \multirow[b]{2}{*}{$P O$} \\
\hline & $\begin{array}{l}\text { Rural } \\
\text { M土DP }\end{array}$ & $\begin{array}{l}\text { Urbano } \\
M \pm D P\end{array}$ & & & & \\
\hline Rejeição de Proximidade & $32.048 \pm 4.903$ & $30.839 \pm 4.640$ & 2.932 & .088 & .015 & .399 \\
\hline Homopatologização & $11.885 \pm 7.036$ & $9.230 \pm 5.432$ & 8.201 & .005 & .042 & .813 \\
\hline Heterossexismo Moderno & $21.164 \pm 6.248$ & $21.207 \pm 5.243$ & .013 & .908 & .000 & .052 \\
\hline Suporte & $21.606 \pm 5.376$ & $22.540 \pm 5.247$ & 1.414 & .236 & .008 & .219 \\
\hline
\end{tabular}


lino. Quanto ao efeito de magnitude verifica-se que este é baixo $\left(\eta_{p}^{2}=.028\right)$ e o poder observado também $(P O=.404)$.

Relativamente à comparação entre os dois grupos etários ( $\leq 25$ anos e $\geq 50$ anos) obteve-se $\mathrm{F}_{(4.184)}=26.450, p=.001, \eta_{p}^{2}=.365$, Wilks $-\lambda=.635, P O=1.000$. Verificam-se diferenças estatisticamente significativas entre os jovens adultos e adultos, uma vez que o valor de prova é $<.05$ (.001). O efeito de magnitude é elevado
( $>$.14) e o poder observado é máximo.

Através da análise do quadro 4, verifica-se que existem diferenças estatisticamente significativas nas quatro subescalas, uma vez que o valor de prova é $<.05$. Os efeitos de magnitude são todos elevados ( $>$.14) à exceção da subescala negativa Rejeição de Proximidade que tem um efeito baixo. Quanto ao poder observado verifica-se que é máximo em três das subescalas e elevado (.876) na subescala Rejeição de Proximidade.

Quadro 4

Médias (M), desvio-padrão (DP) e efeitos das dimensões da perceção acerca da homossexualidade por idade

\begin{tabular}{|c|c|c|c|c|c|c|}
\hline & \multicolumn{2}{|c|}{ Idade } & \multirow{2}{*}{$F$} & \multirow{2}{*}{$p$} & \multirow{2}{*}{$\eta_{p}^{2}$} & \multirow{2}{*}{$P O$} \\
\hline & $\begin{array}{c}\leq 25 \\
\mathrm{M} \pm \mathrm{DP}\end{array}$ & $\begin{array}{c}\geq 50 \\
M \pm D P\end{array}$ & & & & \\
\hline Rejeição de Proximidade & $30.421 \pm 2.723$ & $32.566 \pm 6.054$ & 9.799 & .002 & .050 & .876 \\
\hline Homopatologização & $6.947 \pm 3.256$ & $14.365 \pm 6.764$ & 97.126 & .001 & .342 & 1.000 \\
\hline Heterossexismo Moderno & $18.621 \pm 4.940$ & $23.719 \pm 5.477$ & 48.074 & .001 & .205 & 1.000 \\
\hline Suporte & $24.263 \pm 4.418$ & $19.823 \pm 5.242$ & 42.744 & .001 & .186 & 1.000 \\
\hline
\end{tabular}

Os resultados sobre a religiosidade (quadro 5) foram $\mathrm{F}_{(4.184)}=6.046, p=.001, \eta_{p}^{2}=.116$, Wilks $-\lambda=.884, P O=.985$. Ao nível de significância de $5 \%$ é possível afirmar que existem diferenças significativas entre os indivíduos que se consideram religiosos e aqueles que não se consideram, nomeadamente nas variáveis Homopatologização $(p=.001)$, Heteros- sexismo Moderno $(p=.001)$ e Suporte $(p=$ .006). O efeito de magnitude é moderado $\left(\eta_{p}^{2}\right.$ $=.116)$, nomeadamente na Homopatologização $\left(\eta_{p}^{2}=.077\right)$, Heterossexismo Moderno $\left(\eta_{p}^{2}=.101\right)$ e pequeno no Suporte $\left(\eta_{p}^{2}=\right.$ .039). O valor obtido para o poder observado geral foi elevado $(P O=.985)$, tal como em três subescalas.

Quadro 5

Média (M), Desvio-Padrão (DP) e efeitos das dimensões da perceção acerca da homossexualidade de acordo com a religiosidade

\begin{tabular}{ccccccc}
\hline \multicolumn{2}{c}{ Religiosidade } & & & & \\
\cline { 2 - 2 } $\begin{array}{c}\text { Religioso } \\
\text { M DP }\end{array}$ & $\begin{array}{c}\text { Não Religioso } \\
M \pm D P\end{array}$ & $F$ & & $\eta_{p}^{2}$ & $P O$ \\
$31.693 \pm 5.125$ & $30.781 \pm 3.380$ & .904 & .343 & .005 & .157 \\
$11.540 \pm 6.813$ & $7.512 \pm 3.648$ & 15.556 & .001 & .077 & .975 \\
$22.053 \pm 5.771$ & $18.000 \pm 4.728$ & 21.015 & .001 & .101 & .995 \\
$21.593 \pm 5.377$ & $23.634 \pm 4.857$ & 7.588 & .006 & .039 & .782 \\
\hline
\end{tabular}

\section{DISCUSSÃO}

O presente estudo de caráter transversal teve como objetivo perceber de que forma é vista a homossexualidade na atualidade e a 
influência de fatores sociodemográficos estudando uma amostra representativa. Assim, foi possível constatar que os homens, os indivíduos que passaram a maior parte da sua vida em meio rural, as pessoas com mais idade, os indivíduos que se consideram religiosos, aqueles que não possuem contacto com LGBT, os que possuem habilitações académicas mais baixas (até ao $6^{\circ}$ ano) e por fim os indivíduos que trabalham numa área do setor secundário são mais homofóbicos.

Relativamente às diferenças na perceção da homossexualidade entre homens e mulheres não se verificaram diferenças estatisticamente significativas. Conforme é possível verificar, não houve efeito de magnitude, ou seja, não é possível extrapolar os resultados para a população em nenhuma subescala. Quanto ao poder observado, a probabilidade de num estudo futuro utilizando uma amostra semelhante obter-se os mesmos resultados é baixa.

No entanto, através da análise das médias é possível verificar que os valores obtidos para as mulheres, na subescala positiva Suporte, são mais elevados do que os obtidos para os homens. Relativamente às subescalas negativas as mulheres apresentam valores inferiores aos homens. Assim, existe uma aceitação mais favorável por parte as mulheres em relação à homossexualidade quando comparadas com os homens. Este resultado é semelhante aos resultados obtidos em vários estudos que afirmaram que os homens são mais homofóbicos do que as mulheres (Feng et al., 2012; Gato et al., 2015; Gomes \& Serôdio, 2014; Gusmão et al., 2016; Reis et al., 2016). Também Gato et al. (2012) que usaram o mesmo instrumento do presente estudo verificaram que as mulheres revelavam valores mais baixos nas subescalas negativas e mais elevados na subescala positiva.

No que respeita à influência do meio (rural/ urbano) na perceção da homossexualidade, através da análise dos dados foi possível observar diferenças estatisticamente significativas, entre indivíduos que passaram a maior parte da sua vida em meio rural ou urbano, na perceção da homossexualidade, sendo que o valor da média para a subescala positiva Suporte foi superior nos indivíduos de meio urbano. O valor das médias para as subescalas negativas Rejeição de Proximidade e Homopatologização foi superior no meio rural, enquanto na subescala Heterossexismo Moderno verificou-se o oposto. Analisando os resultados obtidos apenas na subescala negativa Homopatologização, existe um efeito de magnitude pequeno, ou seja, viver maioritariamente num meio rural propicia de forma reduzida os juízos morais e patologizadores da homossexualidade. Relativamente ao poder observado, verifica-se uma elevada probabilidade de num estudo futuro, com uma amostra semelhante, serem obtidos os mesmos resultados. Vários estudos concluíram que viver em meio urbano é um fator protetor para as pessoas não-heterossexuais (oferecendo este maiores e melhores redes de apoio social) e de acordo com o presente estudo é possível afirmar que existe uma maior aceitação da homossexualidade em meios urbanos. Este resultado poderá ser explicado pelo facto de as pessoas do meio rural terem pouco contacto com a diversidade no que diz respeito à orientação sexual (Delgado et al., 2014; Feng et al., 2012).

Quanto à relação entre o sexo e o meio na perceção da homossexualidade não se verificaram diferenças estatisticamente significativas, o que significa que viver em meio rural ou urbano e ser do sexo feminino ou masculino não tem diferenças na perceção da homossexualidade. Como o efeito de magnitude para estes dados é baixo, conclui-se que ser do sexo feminino ou masculino e viver no meio rural ou urbano pouco influencia a perceção da homossexualidade, não sendo possível extrapolar os dados para a população. Quanto ao poder observado a probabilidade de num estudo futuro utilizando uma amostra semelhante obter-se os mesmos resultados é baixa.

Quanto à influência da idade na perceção da homossexualidade observou-se que os indi- 
víduos mais jovens tendem a percecionar de forma mais positiva a homossexualidade. Este resultado é reforçado pelos valores obtidos no parâmetro efeito de magnitude, elevado nas subescalas Suporte, Heterossexismo Moderno e na Homopatologização e baixo na Rejeição de Proximidade. Sendo assim possível generalizar os dados das três subescalas com elevado efeito para a população, acontecendo com menor probabilidade a generalização da subescala Rejeição de Proximidade. Quanto ao poder observado, verificou-se que a probabilidade de num estudo futuro se obter os mesmos resultados tendo uma amostra semelhante é elevada. Estes resultados são corroborados por vários estudos que concluíram que os adultos reportam atitudes mais desfavoráveis em relação a pessoas homossexuais do que os jovens. (Costa \& Nardi, 2015; Gomes \& Serôdio, 2014; Nota et al., 2012; Reis et al., 2016). Tal facto poderá ser explicado pela recente inclusão da disciplina educação sexual nos currículos escolares do ensino obrigatório, que informa os jovens sobre os diferentes aspetos que definem a orientação sexual do ser humano entre outras temáticas.

Quanto à religiosidade observou-se que ser religioso influencia de forma negativa a perceção acerca da homossexualidade. Obtiveram-se efeitos de magnitude moderados para a Homopatologização e para o Heterossexismo Moderno, o que significa que ser religioso influencia negativamente a perceção da homossexualidade, uma vez que há uma maior crença nos juízos morais e patologizadores da homossexualidade, bem como, a não-aceitação da homoparentalidade e do casamento entre pessoas do mesmo sexo, podendo estes resultados ser generalizados para a população. Relativamente à subescala positiva observaram-se valores baixos do efeito de magnitude, ou seja, existe uma pequena relação entre a visão positiva da homossexualidade e a religião. Nas três subescalas onde se verificaram diferenças estatisticamente significativas, existe um poder observado elevado, o que significa que há uma elevada probabilidade de obter os mesmos resultados num próximo estudo com uma amostra idêntica. As pessoas religiosas são mais conservadoras e apresentam uma perceção mais negativa acerca da homossexualidade, em que pessoas com altos níveis de religiosidade apresentam atitudes mais homofóbicas sendo a homossexualidade condenada pela religião e influenciadora do juízo de valor e comportamento das pessoas. Sendo essa considerada pecado e desrespeitadora das leis de Deus (Barringer et al., 2013; Chonody et al., 2013; Gomes \& Serôdio, 2014; Gusmão et al., 2016; Harbaugh \& Lindsey, 2015; Pereira et al., 2017; Santos et al., 2017). O presente estudo confirma estes pressupostos no qual a discriminação da homossexualidade por pessoas religiosas pode ser justificada pelo facto de a religião encarar como condenável o casamento homossexual por impossibilitar a procriação, sendo esta uma das crenças basilares ao nível da religião.

Verificou-se que as pessoas que possuem contacto interpessoal com LGBT apresentam valores mais elevados na subescala positiva Suporte e valores mais baixos nas três subescalas negativas. Relativamente ao efeito de magnitude, verificaram-se valores fortes para todas as subescalas com exceção da Rejeição de Proximidade que apresentou um valor moderado. Assim possuir contacto com LGBT influencia positivamente a perceção acerca da homossexualidade podendo este resultado ser generalizado para a população. O poder observado é elevado nas quatro subescalas, ou seja, num estudo futuro a probabilidade de obter os mesmos resultados utilizando uma amostra idêntica é elevada. A existência de contacto interpessoal com LGBT influencia de forma positiva a perceção da homossexualidade (Adela, 2010; Costa \& Nardi, 2015; Cunningham \& Melton, 2012; Feng et al., 2012, Gomes \& Serôdio, 2014). Gato et al. (2012), mostraram que as subescalas negativas da EMAFLG apresentam valores mais elevados em pessoas que não têm contacto interpessoal com não-heterossexuais, acontecendo o inverso na subescala Suporte, 
verificando-se o mesmo no presente estudo. Os presentes resultados poderão ser explicados pelo facto de o contacto com LGBT aumentar o conhecimento/informação desta minoria e promover a sua aceitação. Por outro lado, possuir uma ligação emocional com não-heterossexuais poderá potenciar a perceção positiva acerca da não-heterossexualidade.

Relativamente ao efeito das habilitações académicas verificou-se que a pessoas mais escolarizadas correspondem atitudes mais favoráveis acerca da não-heterossexualidade, ou seja, existe uma forte influência do nível de escolaridade na perceção acerca da homossexualidade, existindo uma probabilidade elevada de extrapolar este resultado para a população. Acerca do poder observado, apurou-se que existe uma forte probabilidade de se obter os mesmos resultados, utilizando uma amostra semelhante, num estudo futuro. Adela (2010), Feng et al. (2012) e Gomes e Serôdio (2014) mostraram que existem atitudes mais favoráveis em pessoas com mais habilitações académicas face à homossexualidade quando comparadas com pessoas com menos habilitações, o que se verificou no presente estudo. Uma explicação para este resultado é que maior escolarização é sinonimo de mais informação/conhecimento acerca da diversidade na orientação sexual para além de ser um meio facilitador para a inclusão social desta minoria e promoção do contacto com a mesma.

Relativamente ao setor profissional obtiveram-se valores mais elevados nas subescalas negativas e inferiores na subescala positiva no setor secundário. Por outro lado, os estudantes foram os que obtiveram o valor mais alto para a subescala positiva e os valores mais baixos para as subescalas negativas. Assim, trabalhar no setor industrial parece influenciar negativamente a perceção da homossexualidade, contrariamente aos estudantes que como já foi referido no presente estudo (mais jovens) parecem ter uma visão mais favorável quanto à homossexualidade. Quanto aos efeitos de magnitude foram todos elevados à exceção da Rejeição de Proximidade que apresentou um valor moderado, ou seja, o setor profissional influência fortemente a perceção acerca da não-heterossexualidade sendo este resultado possível de generalizar para a população em geral. O poder observado das quatro subescalas é elevado o que permite afirmar que num estudo futuro existe uma forte probabilidade de serem obtidos os mesmos resultados.

Para Gato e Fontaine (2012), existe discriminação face à orientação sexual em profissões nos contextos da justiça, saúde e educação o que mostra uma menor aceitação face à não-heterossexualidade. Também o estudo de Garcia e Souza (2010) verificou que existia uma elevada discriminação por parte de bancários perante relações homossexuais nesta profissão do setor terciário. O que não vai ao encontro dos resultados obtidos, uma vez que se verifica uma melhor aceitação da homossexualidade no setor terciário comparativamente com o secundário. É importante referir que foram excluídos da análise estatística o setor primário, desempregados e reformados, uma vez que não foram recolhidos inquéritos em número suficiente para obter dados estatisticamente significativos. Esta situação constituirá uma limitação do presente estudo por não permitir uma visão representativa de todos os setores de atividade. Importa também referir que, relativamente ao setor secundário, apenas foram conseguidos 31 indivíduos. Como se verifica na revisão da literatura, existe pouca informação sobre a influência da profissão na perceção da homossexualidade o que constitui mais uma limitação para a discussão dos resultados.

Outra limitação encontrada neste estudo foi o facto de existir uma subescala (Rejeição de Proximidade) com baixa confiabilidade, não permitindo a generalização dos dados no que respeita a essa subescala. Para além disso, a maioria dos resultados obtidos para essa subescala não foram estatisticamente significativos.

A escala utilizada foi validada junto de uma população jovem (estudantes universitários). 
Como o nosso estudo tem uma amostra que, além de jovens com menos de 25 anos, também é constituída por adultos com mais de 50 anos de idade poderá ser uma limitação no sentido de que a linguagem utilizada na escala poderá não estar adequada à literacia das diferenças faixas etárias e às respetivas habilitações académicas.

Sugere-se que na realização de trabalhos futuros sobre esta temática se inclua a orientação sexual como variável sociodemográfica para que se possa concluir acerca da influência desta na perceção da não-heterossexualidade. Outros estudos deverão debruçar-se sobre a influência da profissão na perceção da homossexualidade, devendo para esse efeito ter uma amostra mais representativa de todos os setores de atividade, uma vez que existe pouca literatura acerca da influência desta variável. Seria interessante realizar um estudo semelhante, cruzando variáveis sociodemográficas de forma a perceber se existe uma amplificação ou não acerca da perceção da homossexualidade (por exemplo perceber de que forma é percecionada a homossexualidade por indivíduos que passaram a maior parte da sua vida no meio rural e trabalham no setor terciário).

Sugere-se a realização de um estudo longitudinal que inclua a aplicação dos instrumentos uma primeira vez e face aos resultados obtidos delinear uma ação de formação acerca desta temática. Após a realização da ação de formação, deverão ser aplicados os instrumentos uma segunda vez para analisar a coerência nas respostas dadas e perceber se após a formação ocorreu uma mudança na perceção acerca da homossexualidade.

\section{CONCLUSÕES}

Em síntese geral concluiu-se que os homens, os indivíduos que passaram a maior parte da sua vida em meio rural, as pessoas com mais idade, os indivíduos que se consideram religiosos, aqueles que não possuem contacto com LGBT, os que possuem habilitações académicas mais baixas (até ao $6^{\circ}$ ano) e por fim os indivíduos que trabalham numa área do setor secundário são mais homofóbicos que os restantes, apresentando valores mais elevados nas subescalas negativas e mais baixos na subescala positiva relativas à perceção da homossexualidade. As caraterísticas sociodemográficas como sexo, meio, idade, religiosidade, contacto interpessoal com LGBT, habilitações académicas e o setor profissional tendem a influenciar a perceção acerca da homossexualidade.

Este estudo contribuiu para o acréscimo da literatura referente às variáveis em estudo, bem como para a importância dos profissionais, nomeadamente os de saúde, adotarem estratégias que permitam uma melhor aceitação do indivíduo homossexual. Com estas descobertas poderão ser desenvolvidas campanhas de sensibilização orientadas para determinado tipo de população identificado como sendo mais homofóbico. Mais, passados que são tantos anos de programas de educação sexual nas escolas, i,porta repensar o real impacto dessas intervenções e estudar formas de alargar programas de educação sexual para outros grupos que ainda se apresentam como resistentes no reconhecimento das liberdades individuais quanto às suas preferências e escolhas de identidade. O estudo foi previamente revisto e aprovado pela Comissão de ética.

\section{Agradecimentos:}

Nada declarado.

Conflito de Interesses:

Nada declarado.

\section{Financiamento:}

Nada declarado.

\section{REFERÊNCIAS}

Adela, M. (2010). Social perception of homosexuality in romania. Procedia Social and Behavioral Sciences, 2, 5726-5730. 
doi:10.1016/j.sbspro.2010.03.935.

Barringer, M., Gay, D., \& Lynxwiler, J. (2013). Gender, religiosity, spirituality, and attitudes toward homosexuality. Sociological Spectrum, 33(3), 240-257. doi:10.1080/02732173.201 3.732903.

Bozon, M., Gayet, C., \& Barrientos, J. (2009). A lLife course approach to patterns and trends in modern lLatin aAmerican sexual behavior. Journal of Acquired Immune Deficiency Syndromes, 1(51), S4-S12. doi: 10.1097/ QAI.0b013e3181a2652f.

Carvalho, C., Pinheiro, R., Martins, D., Simões, A., \& Maceiras, M. (2017). Atitudes face à homossexualidade: uma proposta de avaliação para a intervenção socioeducativa. Itinerarius Reflectionis, 13(2), 1-22. doi: 10.5216/rir.v13i2.47495.

Carvalho, L., \& Philippi, M. (2013). Percepção de lésbicas, gays e bissexuais em relação aos serviços de saúde. Universitas: Ciências da Saúde, 11(2), 83-92. doi: 10.5102/ucs. v11i2.1837.

Chonody, J., Woodford, M., Smith, S., \& Silverschanz, P. (2013). Christian social work students' attitudes toward lesbians and gay men: religious teachings, religiosity, and contact. Journal of Religion \& Spirituality in Social Work: Social Thought, 32(3), 211- 226. doi: 10.1080/15426432.2013.801730.

Costa, A., \& Nardi, H. (2015). Homofobia e preconceito contra diversidade sexual: debate conceitual. Temas em Psicologia, 23(3), 715-726. doi: 10.9788/TP2015.3-15.

Cunningham, G., \& Melton, E. (2012). The moderating effects of contact with lesbian and gay friends on the relationships among religious fundamentalism, sexism, and sexual prejudice. The Journal of Sex Research, 50(3-4), 401-408. doi: 10.1080/00224499.2011.648029.

Delgado, J., Castro, M., \& Ojeda, F. (2014). Características sociodemográficas, bienestar subjetivo y homofobia en una muestra de hombres gay en tres ciudades chilenas.
Cadernos de Saúde Pública, 30(6), 1259- 1269. doi: 10.1590/0102-311X00108413.

Fazzano, L., \& Gallo, A. (2015). Uma análise da homofobia sob a perspectiva da análise do comportamento. Temas em Psicologia, 23 (3), 535-545. doi: 10.9788/TP2015.3-02.

Feng, Y., Lou, C., Gao, E., Tu, X., Cheng, Y., Emerson, M. R., Zabin, L.S. (2012). Adolescents' and young adults' perception of homosexuality and related factors in three asian cities. Journal of Adolescent Health, 50, 552-560. doi: 10.1016/j. jadohealth.2011.12.008

Fleury, A. R. D., \& Torres, A. R. (2007). Análise psicossocial do preconceito contra homossexuais. Estudos de Psicologia, 24(4), 475-486. doi: 10.1590/S0103166X2007000400007.

Garcia, A., \& Souza, E. M. (2010). Sexualidade e trabalho: estudo sobre a discriminação de homossexuais masculinos no setor bancário. Revista de Administração Publica, 44(6), 1353-1377. doi: 10.1590/S003476122010000600005.

Gato, J., \& Fontaine, A. (2012). Atitudes face à diversidade sexual no contexto psicossocial, jurídico, da saúde e educativo. Exedra, (6), 81-103.

Gato, J., Fontaine, A., \& Carneiro, N. (2012). Escala multidimensional de atitudes face a lésbicas e a gays: construção e validação preliminar. Paidéia, 22(51), 11-20. doi: 10.1590/S0103-863X2012000100003.

Gato, J., Fontaine, A., \& Leme, V. (2014). Validação e adaptação transcultural da escala multidimensional de atitudes face a lésbicas e a gays. Psicologia, Reflexão e Crítica, 27(2), 257-271. doi: 10.1590/16787153.201427206 .

Gato, J., Fontaine, A., Leme, V., \& Leme, A. (2015). Homofobia transatlântica: preconceito contra lésbicas e gays em Portugal. Temas em Psicologia, 23(3), 701-713. doi: 10.9788/TP2015.3-14.

Gomes, I., \& Serôdio, R. (2014). A homofobia 
perspetivada à luz da abordagem da identidade social: Níveis de autodefinição identitária e atitude em relação a pessoas homossexuais. Análise psicológica, 32(2), 215-230. doi:10.14417/ap.803.

Gonzaga, L., Praça, A., \& Lannes, D. (2014). As representações sociais acerca do gay entre estudantes da periferia do rio de janeiro. INTERthesis, 11(2), 162-182. doi: 10.5007/1807-1384.2014v11n2p162.

Gusmão, E., Nascimento, B., Gouveia, V., Filho, L., Costa, K., Moura, H., \& Monteiro, R. (2016). Valores humanos e atitudes homofóbicas flagrante e sutil. Psico-USF, 21(2), 367-380. doi: 10.1590/1413-82712016210213.

Harbaugh, E., \& Lindsey, E. (2015). Attitudes toward homosexuality among young adults: connections to gender role identity, gendertyped activities, and religiosity. Journal of Homosexuality, 62(8), 1098-1125., doi: 10.1080/00918369.2015.1021635.

Junior, F., Carvalho, R., \& Ramalho, T. (2013). Homofobia nas instituições públicas e negação dos direitos das travestisdos travestis. Revista Tema, 14(20/21), 63-75.

Kon, A. (1999). Sobre as atividades de serviços: revendo conceitos e tipologias. Revista de Economia Política, 19(2), 64-83.

Leite, E., \& Neto, J. (2013). O discurso da mídia sobre a homossexualidade nas instituições militares. Revista Entretextos, 13(1), 441-463. doi: 10.5433/1519-5392.2013v13n1p.

Maciel, P., \& Garcia, M. (2014). A produção acadêmica sobre a homossexualidade e a identidade docente. Momento, 23(2), 35-54.

Michaels. S., \& Lhomond, B. (2006). Conceptualization and measurement of homosexuality in sex surveys: a critical review. Cadernos de. Saúde Pública, . 2006, $22(7)$, 1365-1374. doi: 10.1590/S0102311X2006000700002.
Nota, J. M., Vilaça, T., \& Mabote, C. (2012). Atitude face à homossexualidade entre futuros professores de biologia para o ensino secundário geral em moçambique. Revista Ibero-Americana de Estudos em Educação, 7(1), 2-27.

Pereira, A., Dias, S., Lima, T., \& Sousa, L. (2017). As crenças sobre a homossexualidade e o preconceito contra homossexuais no ambiente de trabalho. Temas de Psicologia, 25(2), 563-575. doi: 10.9788/TP2017.2-10.

Pereira, G., Varela, C., \& Silveira, G. (2015). O fenômeno do bullying homofóbico nas instituições de ensino: o direito à igualdade sexual e o princípio da dignidade da pessoa humana. Revista Ibero-Americana de Estudos em Educação, 10, 1489-1506.

Poeschl, G., Venâncio, J., \& Costa, D. (2012). Consequências da (não) revelação da homossexualidade e preconceito sexual: o ponto de vista das pessoas homossexuais. Psicologia, 26(1), 33-53.

Reis, M., Ramiro, L., Tomé, G., Fisher, R., Neufeld, \& Matos, M. (2016). A identidade de género e a influência das atitudes face à homossexualidade/ homoparentalidade entre luso-brasileiros. Psicologia, Saúde \& Doença, 17(3), 311-326. doi: 10.15309/16psd170301.

Santos, D. K. (2013). As produções discursivas sobre a homossexualidade e a construção da homofobia: problematizações necessárias à psicologia. Revista Epos, 4(1), 1-25.

Santos, E., Carvalho, C., Nunes, L., \& Silveira, A. (2017). Homofobia internalizada e religiosidade entre casais homoafetivos. Temas em Psicologia, 25(2), 691-702. https:// dx.doi.org/10.9788/TP2017.2-15.

Santos, V. (2012). Homossexualidade no ambiente escolar. LENPES-PIBID de Ciências Sociais, 1(2), 1-17.

(c) BY-NC Todo o conteúdo da revista PsychTech \& Health Journal está licenciado sob a Creative Commons, exceto quando especificado em contrário e nos conteúdos retirados de outras fontes bibliográficas. 